\title{
¿PANORÁMICA DEL TEATRO GALLEGO DE LOS NOVENTA?
}

\author{
Xosé Manuel Fernández Castro \\ C.P.I. de Castro-Baxoi, Miño, A Coruña
}

\section{LO DE SIEMPRE}

La realización de una panorámica del teatro gallego de los noventa depende fundamentalmente de la definición del sustantivo y del adjetivo comprometidos en el título. ¿Qué entendemos por teatro? ¿Cuál es el referente de la construcción teatro gallego? Aunque también habría que considerar si el corte cronológico de los años noventa responde a una cierta unidad emanada de la propia dinámica histórica del teatro gallego o si, por el contrario, no pasa de ser un prejuicio decimal que aumenta los riesgos de arbitrariedad propios de cualquier acotación de un campo de estudio. Del mismo modo, una vez delimitado cronológicamente el objeto, deberíamos cuestionarnos la validez de posibles afirmaciones panorámicas partiendo del volumen y profundidad de las investigaciones de detalle preexistentes.

Rechazamos la vanidosa tentación de pretender ser nosotros quienes dictaminemos lo que es esencialmente cada uno de esos conceptos; 
una especulación con vocación de eternidad reservada para místicos y filósofos con los que no nos atrevemos a lidiar en la arena. Ello no significa que ocultemos nuestra teorización, sólo que no pretendemos que nadie comulgue con ruedas de molino. Bastará con que las hipótesis de partida tengan una cierta validez y que desde ahí cualquiera pueda dar nuevos pasos siguiendo las diferentes direcciones de la rosa de los vientos. Deseamos aferrarnos al método científico para caminar ciegos y a tientas por el caos.

\section{TEATRO Y LITERATURA}

Entendemos aquí por teatro el arte que reúne presencial y ópticamente los dos espacios y los dos tiempos siguientes: (1) el cronotopo diegético del personaje o figura dramática y (2) el cronotopo extradiegético del público y de los materiales con que se construye la fábula. La diégesis funciona como vasculante en torno al que se construye un acto comunicativo reversible en el que tanto las funciones de emisor como las de receptor pueden ser alternativamente ocupadas bien por los materiales con los que se construye la diégesis, bien por el público.

Según esta concepción, el mimo y cierto ballet pertenecerían a la categoría mencionada por más que en ninguno de los dos casos se haga uso de las palabras. Algo que no ofrecería ninguna duda en el caso del teatro lírico: nada impide la utilización de la palabra cantada. También habría que contemplar las lecturas dramatizadas y, desde luego, el teatro de títeres; mas no el teatro radiofónico ni los vídeos de teatro, en el primer caso por no haber reunión presencial ni óptica y en el segundo por la falta de copresencia. Efectivamente, la cita frente un autómata incapaz de reaccionar ante la emisión de un público impide la reversibilidad del acto comunicativo que caracteriza, según nuestra concepción, al teatro. Así que la literatura no es teatro, si bien hay que reconocer que con frecuencia el arte de la palabra muestra sus posibilidades diegéticas colaborando como un arte más en el mundo del espectáculo. Y es que el teatro es un arte propicio para la conjunción de diversas formas artísticas aunque la única necesaria, en nuestra definición, sea la encarnación de una figura dramática en una diégesis, lo que ha facilitado a lo largo de nuestra historia un confusionismo atroz entre teatro y literatura. 
Así pues interesa postular urgentemente una definición de literatura teatral; para nosotros, el conjunto de piezas que empleando como único medio artístico las palabras - lo que implica que su recepción pueda ser puramente linguística - están destinadas a formar parte de la cadena de producción de un espectáculo escénico. María del Carmen Bobes Naves (1994: 242) escoge esta propuesta como síntesis de las polémicas entre los textocentristas y los escenocentristas:

\begin{abstract}
Hoy se ha llegado a un equilibrio y se considera que el teatro se escribe para ser representado, es decir, que su fin es la representación; pero es indudable que puede ser leído y que toda representación implica una lectura previa, en el sentido físico literal y en el sentido hermenéutico, antes de hacer la representación. Todo el texto puede ser leido (el literario y el espectacular) y la diferencia entre uno y otro se da en el escenario y consiste en que el texto literario sigue siendo palabra en la escena, mientras que el texto espectacular no pasa a palabra en la representación, sino que se pone en escena mediante signos no verbales, creando el contexto situacional donde se revive el diálogo.
\end{abstract}

Una definición como ésta, que parte de la finalidad del trabajo, es decir, de la intención del autor, es una definición teleológica que se torna en acientífica fácilmente, cuando los índices que apuntan a esa clasificación no pueden observarse de un modo objetivo. Disponemos de determinados indicadores que permiten calificar con objetividad como literatura teatral algunas piezas concretas, de forma destacable las acotaciones del cuerpo didascálico que sitúan la fábula en el ámbito escénico. No es necesario que toda pieza teatral presente acotaciones, de manera que este índice no basta para establecer la totalidad de los objetos del corpus de la literatura teatral, mas si es claro que se trata de un trazo privativo de la literatura teatral lo que permite otorgarle cierta validez: no estarán todas las que son, mas las que están, son.

Postulamos como cuerpo disdascálico todo el conjunto de palabras de la pieza teatral no atribuidas a las figuras dramáticas, independientemente de cualquier otra consideración de la diversidad posible en las instancias de enunciación. En este sentido seguimos las indicaciones del Equipo Glifo (1998: 32) que abre su entrada de acoutación con las siguientes palabras:

Parte non dialogada do texto dramático onde se atopan as indicacións escénicas do autor para unha posible posta en escena. As acoutacións pertencen ó corpo didascálico (e ó paratextual), composto por todo aquilo que nun texto de teatro non é diálogo, é dicir, todo o que provén da responsabilidade inmediata do autor, dende a lista de dramatis personae ó nome dos personaxes que precede a cada réplica. 
Sin embargo, aún cuando no estén a nuestra disposición ediciones o manuscritos de una determinada obra literaria teatral, lo que nos impedirá demostrar su pertenencia a este género mediante constataciones sobre su cuerpo didascálico, no podemos obviar su adscripción a esta tipología si tenemos constancia de su finalidad teatral a partir de otros indicadores como, por ejemplo, su efectiva puesta en escena. Por extensión, algunas ediciones literarias que prescinden de cuerpos didascálicos podrán presentar otros indicadores que aconsejen su inclusión en el corpus de la literatura teatral lo que se hace frecuente en trabajos con clara intención rupturista de las convenciones al uso.

\section{GALLEGO}

Postulamos como literatura gallega aquella que emplee la lengua gallega como código necesario para que se produza la comunicación entre emisor y receptor. Nos mantenemos en la línea trazada por Carvalho Calero y defendida últimamente por Vilavedera (1994: 211):

[...] emprégase o calificativo galega para aludir estrictamente á producción teatral escrita orixinariamente en lingua galega, non tanto polo que isto ten de risco nidia e obxectivamente diferenciador coma pola evidente vontade que denota nos seus autores de situarense (para ben e para mal) no marco dun determinado sistema literario, regulado por unhas moi concretas regras de xogo.

De ahí que aquellas piezas en las que el uso marginal de la lengua gallega no exija esa competencia lingüística plena por parte del receptor serán marginales, por lo mismo, al ámbito de la literatura teatral gallega. La definición teleológica de la literatura teatral propicia que se le dé relevancia especial al código en el que se expresan las figuras dramáticas, supuesta la permanencia de los diálogos en el espectáculo, lo que le otorga prioridad desde la perspectiva de la comunicación escénica.

\subsection{Teatro gallego}

Recientemente los políticos gallegos han intervenido en una polémica de interés para la definición del teatro gallego a causa de una discusión sobre la adecuación de montar piezas de Valle-Inclán con producción de la compañía institucional del Centro Dramático Galego, a pesar 
de no poder obtener permiso para su traducción a las lenguas cooficiales (¿suboficiales?) de España por la negativa del heredero de los derechos de autor del genial autor arosano. El debate de la comisión parlamentaria ha sido recogido en la Revista Galega de Teatro 18, con intervenciones de los políticos del PP, del BNG, del PSOE y de EU-EG. Ninguno de esos políticos cuestionaba que la función del Centro Dramático Galego fuese actuar como agente normalizador de la cultura gallega. Sin embargo, sus posturas resultaron irreconciliables; fuera de diversas tensiones partidistas explicitadas en el debate, se justificaban las propuestas divergentes apoyándose en distantes concepciones de definición del teatro gallego de corte teórico o práctico, que sospechamos extrapolables a la concepción general de la cultura gallega.

Para los representantes de EU-EG y del BNG se distingue entre (1) teatro gallego, entendiendo por tal el conjunto de los espectáculos en lengua gallega, y (2) el teatro galego de seu (netamente gallego) como aquél cuyo texto está originalmente escrito en gallego; es, pues, una definición de corte filológico. Para el representante del PSOE, más importante que la lengua, corazón de una cultura, es el cerebro, aludiendo a argumentos antropológicos no explicitados, de manera que la galleguidad antropológica de la obra de Valle-Inclán justificaría una producción entre el CDG y el Centro Dramático Nacional (de España). Los representantes del PP no entran en la definición del teatro gallego, pero cuando repiten uno tras otro la excepcionalidad de este montaje parecen admitir, por omisión, la definición filológica; aunque por encima de los principios de identidad asumen la excepcionalidad, representando el papel de pragmáticos, es decir, flexibles en la identidad, inflexibles en el pragmatismo. En honor a la verdad, la excepcionalidad no ha sido tal, puesto que en la estela del montaje sobre Valle-Inclán, que, en contra de la opinión pública, se haría efectivamente, entraría el Aula de Teatro de la Universidade de Santiago de Compostela (Revista Galega de Teatro 19: 73) que estrenaría en el Teatro Principal de Santiago el día 14 de diciembre de 1998 (Revista Galega de Teatro 19: 58), con lo que se ha producido un hecho excepcional en la Galicia de los noventa, teatro en lengua castellana con producción institucional.

\subsection{Surtido de identidades}

Tenemos, pues, por lo menos tres definiciones del teatro gallego: la pragmática, la antropológica y la filológica. En la visión pragmática, 
la definición de galleguidad se subordina a la posibilidad de encajar las diversas piezas gerenciales de un negocio: la comparecencia del gerente del IGAEM en el debate no hace más que subrayar esta perspectiva. La visión antropológica es, lamentablemente, demagógica por contener una contradicción de términos interna: si Valle-Inclán pertenece con total derecho a la cultura teatral gallega carecería de sentido que se exigiese, como hacía el PSOE, una coproducción con el Centro Dramático Nacional; en el fondo parece primar también la visión pragmática, aunque de modo solapado. La visión filológica, que echa sus raíces en las teorizaciones sobre literatura gallega, formuladas por Ricardo Carvalho Calero, da para definir la mayor parte del teatro que se hace en Galicia, salvo el minoritario teatro mudo, y las contadísimas excepciones de teatro en castellano, pero exige apoyarse en un concepto previo: la lengua gallega. $Y$ es que a la luz de la política de negación de subsidios a los trabajos que han optado por formulaciones normativas no oficiales, cualquiera diría que el partido gobernante sólo admite como gallega la oficial.

En nuestro trabajo emplearemos la teoría filológica como hipótesis no sólo en la definición de literatura teatral gallega, sino también en la de teatro gallego. La clave filológica es aplicable a todo el teatro de palabras, mayoritario, hablado o cantado, por lo que en ese ámbito parece innecesario establecer nuevos criterios. Mas nuestra definición inicial de teatro daba cabida a otros ámbitos mudos que exigen delimitación por lo que aceptaremos como rasgo determinante la nacionalidad de la producción; el mismo criterio que funciona como oficial en la marca de origen Galicia calidade, que exige la galleguidad de todos los pasos en la cadena creativa.

Así pues será teatro gallego (1) el que esté hecho sobre un texto escrito originariamente en lengua gallega, (2) el que emplee una traducción gallega de un texto escrito en otro idioma y (3) aquel teatro mudo cuya cadena de producción completa sea gallega. Otra cosa sería hablar del teatro en Galicia donde habría que dar cuenta de los montajes institucionales sobre Valle-Inclán y, además, de las giras por nuestro territorio practicadas por compañías de cualquier otro lugar del mundo.

De modo que el teatro gallego comparte dos perspectivas esencialmente diferentes. Por un lado, está el interés por Galicia como lugar de explotación y, de otro, Galicia como lugar de producción. Cualquier compañía, sea cual fuere su origen puede tener interés por Galicia, su público y sus auditorios. Es en este ámbito en el que consideramos 
apropiado hablar del teatro en Galicia, y ahí no importa el acento con el que debamos pronunciar el nombre de la compañía, del director o del autor, el nombre puede ser catalán, inglés o de la China. Otra cosa muy distinta es que además del interés de distribución, Galicia sea lugar de producción, en ese caso podríamos encontrarnos con compañías nacidas para la autarquía, para el autoabastecimiento, al lado de otras exportadoras. Claro que, llegados a este punto, observamos algo sorprendente: aquéllas que se muestran partidarias de fichar figuras de fuera no son exactamente las que compiten en mercados exteriores, más bien sucede lo contrario, el producto con denominación de origen más cerrado es el que mejor se exporta.

\subsection{Familia y clan}

Es, luego, la producción, la clave para conceder la denominación de origen Teatro Gallego. No importa que la comunidad gallega productora haya vivido dentro de las actuales fronteras o en el éxodo, algo familiar para cualquier republicano español, allí donde los gallegos se reunían invocando el nombre de Galicia y hacían teatro, era teatro gallego; tenemos derecho a reclamar como propio el teatro gallego en Argentina, lo que es ya ir bastante lejos. Pero la década de 1950, abierta con el estreno americano de Os vellos non deben de namorarse y cerrada por $O$ incerto señor Don Hamlet, príncipe de Dinamarca, el balanceo entre teatro gallego en el exterior y en el interior no ha hecho más que decantarse hacia este último: aquel se ha quedado en el aire y la producción interior se ha asentado firmemente en la arena del parque. Hoy no tenemos compañías argentinas o uruguayas en nuestro territorio que nos devuelvan la visita girada, tenemos, eso sí, personas que han probado fortuna fuera del país y que se han integrado en otros teatros nacionales (Valle-Inclán, María Casares, Lauro Olmo...), mas no hay casos de compañías gallegas que se hayan instalado de modo estable fuera de la comunidad autónoma en los últimos años, a la vez que las antiguas se han ido marchitando. Paralelamente, hay personas de fuera de Galicia que se han ido integrando en el teatro gallego, como, por ejemplo, Marcos Orsi desde finales de los ochenta, procedente de Arte Livre de São Paulo, Brasil, a quien acabamos de ver en el último montaje institucional del Centro Dramático Galego, bajo la dirección del italiano Fabio Mangiolini. 
Estas dos últimas personas mencionadas tienen en común con Galicia algo que ya ha demostrado la Lingüística Románica: la lengua latina, lo que no es decir poco de una cultura. Cierto es que la hostia depositada sobre esa lengua es más carolingia que romana en nuestro caso, como no deja de recordárnoslo intermitentemente el camino jacobeo, también nuestra música es esencialmente céltica; además de la familia nos interesa el clan. Dos estructuras sociales de enorme interés para conocernos a nosotros mismos ahora que ya nos reconocemos y nos reconocen a través del marco político de la Xunta de Galicia. El que ahora la preside, y se han cumplido ya diez años, Manuel Fraga Iribarne, anticipó su cambio de jurisdicción en el verano de 1987, empleando como eslogan una imagen familiar en la que identificaba Galicia con su madre y España con su padre, claro que el que no tardaría en dirigir San Caetano dio a entender muchas más cosas en su símil; Galicia era para él una madre doliente y un buen hijo debe acudir antes a su madre que a su padre, utilizando para su comunicación un arquetipo familiar penosamente sexista, pero que llovía sobre mojado por la defensa del concepto de Galicia Madre, idea regionalista centenaria que consiguió sobreponerse a la retórica imperial de la Madre Patria. Sin embargo, en lo sucesivo Fraga defenderá una postura que podemos calificar de bipátrida, de doble nacionalidad, en la que Galicia abandona su papel de madre doliente substituido por el de chica: España, madre patria; Galicia, patria chica. Otra imagen de Galicia, no chica sino señora, ha sido reclamada por la élite nacionalista, al menos desde Ramón Cabanillas. Todavía queda otro sector que defiende haber superado el primitivismo nacional, y, cómo no, el nacionalista, sosteniendo un discurso internacionalista donde la clase social parece haber sido su punto de referencia, sin embargo, han cortado la mundialización a la altura de Europa y el obrerismo a la de la clase media; no han dejado por ello de declararse galleguistas, aunque eso no les ha impedido zancadillear la Lei de Normalización Lingüística que merced a sus actuaciones ha sido declarada anticonstitucional, al tiempo que han resultado beligerantes contra la toponimia autóctona. Todos se declaran galleguistas, aunque el rol de Galicia, señora, chica o fantasma, sea bien diferente. El referente familiar parece claro.

Si tradicionalmente el clan era para la mayoría de la población su aldea o parroquia y esa visión está todavía viva, también es cierto que la estructura política del Estado ha propiciado un nueva dinámica que partiendo del partido político continúa su ascenso jerárquico en el ámbito, casi exclusivo, de las instituciones: municipio, diputación, 
Xunta, Madrid, Bruselas. Y es que los partidos políticos, más unos que otros, han sabido atraer con gran fuerza la mayor parte de las estructuras preexistentes, integrándolas en un proyecto político de conjunto que, de un modo $\mathrm{u}$ otro, sostienen un techo determinado de patria (Galicia, España, Europa). Al lado de la Madre Patria, el techo del Padre Clan permite comprender, por ejemplo, la enorme heterogeneidad de partidos que conforman el frente del BNG, la dinámica federal del PSdG-PSOE o la obediencia al líder nacional, el de Madrid, del PP. Tal vez haya sido el PSdG el que más haya dejado de lado la implantación territorial, mientras que la mayoría de los clanes preexistentes se han integrado en el PP, mientras que el BNG ha conseguido captar una buena parte de las redes profesionales, especialmente cuando en su base se han dado las condiciones para llevar adelante alguna lucha sindical, coordinable en un proyecto intersectorial de defensa del tejido productivo gallego.

Así las cosas, el teatro como industria cultural, partiendo en buena medida de una élite cultural antifranquista ha ido abandonando las tesis simplemente progresistas para ser mayoritariamente integrado desde su base profesional en el clan que tiene como techo Galicia, coordinándose en el proyecto intersectorial nacionalista. Sólo que el poder ha continuado en manos de clanes territoriales previos y, a la par, el proyecto nacionalista es una hidra con tantas cabezas como concepciones sociales, en donde la aproximación al control de las instituciones está generando nuevos clanes territoriales. En estas revueltas aguas han de bucear las gentes de nuestro teatro papándose unos a otros en una reducida plataforma costera humana de menos de tres millones de habitantes, repartidos en numerosos nichos ecológicos que no dejan de conformar un ecosistema complejo.

\section{LOS AÑOS NOVENTA}

Tenemos la impresión de que las características típicas de la Galicia de los noventa no son sino continuación de otras tendencias que se hacen explícitas ya en la segunda mitad de los ochenta. De manera que 1991 no supone el inicio de una época característica, por el contrario consideramos que se hace necesario remontarse algunos años atrás. 


\subsection{Apuntes sociales}

Así parece acontecer examinando los datos demográficos que tenemos a nuestra disposición. A pesar del fuerte movimiento migratorio recurrente en Galicia, el crecimiento de la población a lo largo de la historia es una tendencia constante que, sin embargo, se rompe en la actualidad. «No censo de 1991 rexístrase un descenso de máis de 163.000 habitantes» (Galicia 1999, 1998: 30) si lo comparamos con el de 1978, pasándose de 2.895.469 a 2.731.669. Pero esto es fruto de una tendencia que se ve clara ya en 1986, momento en el que por vez primera sufrimos un crecimiento vegetativo negativo, $-0,1$ (Obelleiro, 1991: 227). Así, durante 1997 Galicia se sitúa como la segunda comunidad autónoma por su bajo índice de natalidad, 0,89 hijos por cada mujer, mientras que España, con 1,16, es el Estado menos fecundo de la Unión Europea. De modo que «O índice de fecundidade en Galicia non garante a substitución xeracional» (Galicia 1999, 1998: 31).

Los datos económicos apuntan en la misma dirección. El saldo del comercio exterior gallego cuatriplicará sus perdidas entre 1985 y 1990, pasándose de 25.450 millones a 113.611 , siempre en números negativos. En esta misma línea acabamos de conocer los datos correspondientes a 1998 con pérdidas muy superiores: se sobrepasan los 400.000 millones.

Desde la perspectiva política, la Galicia de los noventa se caracteriza por la presidencia en la Xunta de Manuel Fraga Iribarne, quien desembarcó en su tierra de origen con las elecciones autonómicas de diciembre de 1989. De este modo los conservadores gallegos resolvían la crisis de 1986-1987 en la que llegaron a dimitir todos los conselleiros y a la que temporalmente se le había dado una puntada final con la moción de censura que puso el poder bajo una batuta tripartita compuesta por los nacionalistas del Partido Nacionalista Galego-Partido Galeguista y de Coalición Galega junto con el Partido dos Socialistas de Galicia-PSOE (Beramendi, 1996). El año 1986 también se caracteriza en la política gallega (1) por la reformulación del Partido Comunista Galego en Esquerda Unida, (2) por la convergencia estratégica con el Partido Socialista Galego-Esquerda Galega del Bloque Nacionalista Galego que acepta luchar dentro del marco autonómico, (3) por la aparición de la organización terrorista del Exército Guerrilheiro do Povo Galego Ceive, y (4) por un notable cambio de rumbo del sindicalismo agrario que se centra en la defensa del tejido productivo del campo gallego. 
Así pues, mientras que la primera mitad de los años ochenta se caracterizó por el inicio de una contundente reconversión industrial y por el establecimiento del marco autonómico, la segunda mitad estará marcada por el ingreso de España en la Comunidad Económica Europea, proceso cronológicamente coincidente con la perestroica soviética, lo que produce un impacto sin precedentes en nuestra demografía, economía y política, marcando claramente las tendencias características de los noventa.

\subsection{Apuntes culturales}

De un modo parejo se comporta nuestra cultura a la luz de diversos datos extraídos de las dinámicas de los sistemas literario y teatral gallegos.

El mundo editorial sufre un cambio económico importante como ha constatado González-Millán (1994: 73-4):

Convén engadir, sen embargo, e esta observación é válida sobre todo a partir de 1985, que o prezo do libro galego non inflúe negativamente na súa difusión e comercialización e que é incluso inferior ao libro en castelán, especialmente cando se trata de novidades.

Ese cambio en la situación económica editorial parece haber influido de modo determinante en las diversas composiciones literarias propias de la época:

Sen embargo, a partir de 1985, e coas dificultades e contradiccións propias dunha cultura en proceso de normalización e deficientemente institucionalizada, experimentariase unha crecente comercialización que ia repercutir de forma directa na lenta pero inevitable transformación do libro galego de "signo de militancia ideolóxica" en "obxecto de consumo», dende as fases iniciais da creación autorial e producción editorial ata a súa difusión e recepción (González-Millán, 1994: 67).

Uno de los cambios más notables puede detectarse en la jerarquización de los géneros del sistema. Si pensamos en la importancia del premio Xerais de novela que data de 1984 y del Merlín de narrativa infan- 
til de la misma editorial, que es convocado desde 1986, veremos que la tradicional preponderancia de la lírica comienza a ceder ante la narrativa, que, además, toma nuevos rumbos:

A mediados dos 80 estaba claro que, en contra da opinión dun determinado sector da crítica, se perfilaba no mundo da narrativa unha xeración máis libre, máis individualista e máis cosmopolita; e observábase unha vontade de ruptura co mundo pechado das tradicións literarias máis inmediatas, excesivamente ruralistas e localistas [...] (González-Millán, 1994: 178).

Con esta constatación han coincidido también expertos en nuestra lírica, situando en 1987 (Rodríguez, 1997: 11) una importante crisis como lo muestra el hecho de que algunas voces importantes de la década se silencien ante los lectores:

Algúns premios desaparecen, desaparecendo con eles as coleccións de poesía que os sustentaban, as editoriais reducen o número de publicacións de poesía e os recitais deixan de ser algo habitual. A escrita poética dos autores dos 80 - da maioría, enténdase-faise embrionaria e non saen á luz máis que en contadas ocasións: colaboracións nas revistas que sobreviven ou recitais entendidos como actos illados de homenaxe.

Parece que esa misma crisis afectó a la estructura de producción teatral por medio de las refundaciones. De hecho, hay que fechar en torno a mediados de los ochenta un nutrido grupo de las actuales compañías teatrales gallegas más emblemáticas. En esa lista podemos citar las siguientes: Centro Dramático Galego (mayo de 1984, aunque funcionaría sin cobertura legal hasta abril de 1986 para integrarse en el IGAEM en abril de 1989), Teatro do Atlántico (1985), Teatro do Noroeste (1986), Matarile-Sala Galán (1986), Teatro da Lúa (1987), Chévere-Sala Nasa (1987), Teatro do Malbarate (1987), profesionalización de Sarabela (1987), Compañía Tranvía (1989, que se fundirá con Ollomol en 1993), Teatro de Morcego (1989), etc. (Varios, 1996: 27-36). Es destacable la salida de escena de la Compañía Luís Seoane en 1987. También se producirá por estas fechas la fundación de la Asociación de Actores, Directores e Técnicos de Escena (1985), la puesta en marcha de los circuitos teatrales (1985) y en junio de 1988, otro hito en la cronología de nuestro teatro, el Primeiro Encontro do Teatro Profesional Galego en Ferrol. Al año siguiente se creará el IGAEM, al que se adscribirá el Centro Dramático Galego tal como hoy opera, de modo que entre 1984 y 1989 se produce la regularización de la compañía ins- 
titucional y, paralelamente, la refundación de una buena parte del teatro profesional privado.

\subsection{Apuntes taxonómicos}

Efectivamente, la taxonomía hoy más extendida tanto para el teatro como para la literatura teatral gallega sitúa su punto de inflexión en medio de la década de los ochenta. Vieites (Varios, 1996: 11) sitúa en 1984 el inicio del período escénico del teatro institucional y para la literatura teatral (Vieites, 1998a: 149) un año más tarde, en 1985, con el primer despunte de la generación de los noventa.

Sobre la generación literaria, Paz Gago y Vilavedra (Varios, 1996: 20-23 y Vilavedra, 1998: 300) mantienen una división simplificada a la que llamarán Generación Post-Abrente en la que se acumulan las generaciones de los ochenta y de los noventa de Vieites.

En nuestra opinión resulta pertinente la división del Nuevo Teatro (1965/1999) de Vieites donde distingue (a) el teatro independiente (1965/1978), (b) el teatro profesional (1978/1984) y (c) el teatro institucional (1984/1999), aunque consideramos que la fecha final de esta última etapa debiera dejarse abierta.

No concordamos, sin embargo, con la división de la literatura teatral que Vieites establece para la Nueva Dramaturgia (1969/1999) y que presenta en tres subgrupos: (a) el grupo de Ribadavia (1969/1977), (b) la generación de los ochenta (1977/1985) y (c) la generación de los noventa (1985/1999). Puestos a hacer divisiones generacionales valoramos más útil didácticamente la que marca dos grupos, ensayada por Paz Gago y Vilavedra, en generación Abrente y generación Post-Abrente, aunque en su trabajo conjunto bajo el epígrafe de Generación Post-Abrente aparezcan autores nacidos en años muy separados para lo que sería de esperar en una generación: Manuel Riveiro Loureiro (1933), Xesús Pisón (1954) o Miguel-Anxo Murado (1965).

Para nosostros, el núcleo central de la primera generación, la Abrente, estaría constituido por autores entre los veinte y los treinta años durante 1973. El segundo segmento lo compondrían autores entre los veinte y los treinta años en 1988. Aceptando la existencia de la gene- 
ración Abrente, dudamos seriamente de la pertinencia del concepto de generación para el segmento Post-Abrente y preferimos referirnos a este grupo como Des-Generación para recordar hasta qué punto están desarticulados como colectivo por más que pertenezcan a la misma banda natal. Consideramos que esta misma percepción hizo que Paz Gago y Vilavedra (Varios, 1996: 21) se refirieran a este grupo como generación fantasma y es que las expectativas en las que trabajan son desalentadoras:

En estas condiciones, ¿quién se anima a escribir teatro? Pues en buena parte aquellos dramaturgos que, por sus vinculos con determinadas compañías, tienen relativas posibilidades de hacer llegar sus obras al público gallego, si no por vía textual, si por vía escénica (Varios, 1996: 21-22).

Para alcanzar una cabal periodización de la literatura teatral de los últimos tiempos consideramos preciso marcar más que la cuestión generacional la de los tiempos: el período de Ribadavia, de 1973 en adelante, y el institucional, de 1988 en adelante. El papel ultramarginal de la literatura teatral gallega no impide que podamos situar en 1988 un hito fundamental para su institucionalización. Nos referimos a la primera edición del premio Álvaro Cunqueiro, en la que salta a la palestra pública un joven escritor nacido en 1966, Roberto Salgueiro.

Así pues, durante los tiempos de Ribadavia, de 1973 en adelante, los propios del teatro independiente e inicios del profesional, destacará en la literatura teatral la Generación Abrente compuesta por autores nacidos entre 1943 y 1953, aunque continúen activos otros de más edad y aparezcan ya algunos tan jóvenes como prematuros que se suman al momento. Durante los tiempos institucionales, segunda mitad de la década de los ochenta, los propios del teatro institucional, continuarán en activo determinados miembros de la generación Abrente, aunque también se incorporarán a la literatura teatral algunas personas de su misma edad, e incluso mayores, y sobre todo los candidatos a una nueva generación tan desarticulada que mejor podría llamarse Des-generación, nacidos fundamentalmente entre 1958 y 1968, que irán adquiriendo protagonismo hasta que se alzan con el primer premio institucional de literatura teatral gallega, el Álvaro Cunqueiro, e irán estabilizando su prestigio a lo largo de la década de los noventa. 


\section{PANORÁMICA HORIZONTAL}

Cuando en cinematografía hablamos de panorámica, pensamos en un trípode firmemente anclado al suelo, con la burbuja de nivel en su sitio y la cámara presa salvo en el movimiento lateral de su ojo a izquierda o derecha. Pero sólo si la cámara está en el centro de un círculo de motivos, éstos son retratados por ella de modo equidistante, mientras que al tomar una fila habrá objetos en primer plano y otros en segundo o en tercero...

Algo así sucede si optamos por un punto de vista panorámico en la observación de una expresión cultural. La teoría de la que partimos es como el trípode que nos une a la tierra. Los argumentos de esa teoría actúan como la burbuja de nivel. El movimiento lateral se da en el tiempo, tal vez desde el pasado hacia el presente, en todo caso de manera que un tiempo estará en primer término y otro en segundo. En nuestra planificación, el punto de situación de la cámara es, a nadie le sorprenderá, el actual; hacia atrás los objetos se van diluyendo, se hacen más pequeños y desenfocados, permitiendo que entren en campo más elementos del entorno.

Es fácil que, aplicando nuestra sensibilidad actual, metamos en el mismo cajón de estéticas obsoletas las diversas muestras artísticas del pasado como si éste fuese un conjunto continuo homogéneo y la renovación o experimentación, patrimonio exclusivo de algunos de nuestros contemporáneos; lo que se deriva de la ignorancia sobre la tradición que nos ha traído a donde estamos. La marginalidad editorial de la literatura teatral favorece esta carencia de memoria histórica, lo que caracteriza de modo aún más marcado la escena por su irrepetibilidad. Lo cierto es que desde el pseudocasticismo de las primeras muestras de bilingüismo pintoresquista hasta el costumbrismo choqueiro hubo un salto, como cuando este costumbrismo se tornó dignificador. Desde ahí también se produjo una renovación con un intento de instrumentalización social que a su vez iría abriendo paso a ensayos compositivos simbólicos o alegóricos de renovación del naturalismo, proceso que no pudo completarse por mor de la Guerra Civil española y que se reemprendería en el ámbito de Ribadavia.

También en los años ochenta la decepción de la utopía de las izquierdas traerá un nuevo cambio; si el teatro no es un instrumento para cambiar la sociedad, tal vez pueda considerarse el mejor campo para cambiar al teatro mismo. El teatro se autocontempla y descubre 
que debe ser una empresa que dé resultados en el mercado, la otra mano en la que comer, la de los políticos, inspira aún mayor desconfianza. Es tiempo de reconversión (renovación no reinvención), hay que ofrecer cuentas de resultados para que una gran industria profesional demuestre la capacidad de la élite cultural que tanto hablaba. El teatro lanza su red sobre un público más numeroso y concluye que debe ser más comunicativo, por lo que retoma los campos humorísticos (también los cómicos e irónicos) y la investigación en el virtuosismo.

Llegamos a una situación en la que aquellas tres formas de teatro descritas por Passolini durante el 68 pueden englobar las ofertas actuales: la charla, el grito y la palabra. El teatro de la charla recupera la comedia, el del grito recupera el ritual, en el de la palabra se ahonda en la complejidad morfológica de los signos implicados. Entra en crisis el distanciamiento y el teatro adquiere mayor significado social cuanto mayor sea la empatía de los espectadores, y ésta se mide en términos globales por el número de entradas, es decir, también de hábito y de fidelidad, lo que apunta a la mayor de sus creaciones, un público más numeroso. El teatro quiere un patio fuerte de butacas, afectivamente próximo; la oferta debe ser eficaz aunque para ello deba echar mano de efectismos humorísticos o virtuosistas, pero sin olvidar que tiene delante un público variado de juglares, segreles y trobadores, por lo que deberá transmitir en multifrecuencia para asegurar el contacto con tan diversos receptores; cueste lo que cueste hay que romper con una retórica que ya se siente liturgizada, es necesario presentar signos revulsivos contra la generación del 68 .

\section{BIBLIOGRAFIA EN NÚMEROS ROJOS}

No es fácil hacer una panorámica del teatro y de la literatura teatral de la Galicia más reciente. El objeto es lo suficientemente rico como para obligarnos a actuar con agresividad en la selección y, lo que todavía resulta más determinante, el acervo de trabajos previos que hayan dado cuenta del objeto con rigor y exhaustividad es demasiado parco. En 1998 ha llegado a nuestras librerías un ejemplo único, coordinado por Manuel F. Vieites (1998b: 13), quien reconocía la pretensión panorámica afrontada con un trabajo colectivo, aunque sobre un período que partía de otro corte cronológico: 
O obxectivo deste volume non é outro que ofrecer unha primeira aproximación ou panorámica xeral, cunha perspectiva fundamentalmente divulgativa, sobre unha etapa determinante da nosa historia literaria e teatral, aquela que vai de 1965, ano no que se crea o grupo de teatro de Asociación Cultural O Facho, e 1995, no que se cumprian trinta anos daquela efeméride teatral.

Un problema limita las posibilidades de esa panorámica (Vieites 1998b: 12):

Canto a investigación, habería que sinalar que, agás excepcións certamente salientables, a situación do estudio crítico da nosa literatura dramática é ben pouco significativo, mentres os estudios teatrais están aínda por formular e por ocupar os espacios académicos e institucionais necesarios para o seu desenvolvemento.

\section{ESPECTÁCULOS, ESPECTÁCULOS Y ESPECTÁCULOS}

Bastará con ofrecer los datos que hemos podido recopilar sobre estrenos, cronológicamente organizados, del teatro profesional gallego durante los primeros cinco meses de 1998 para que el lector se haga una idea de la riqueza y dispersión de nuestra escena y de la dificultad que entraña una visión panorámica en el estado larvario de nuestra institución crítica. En esta muestra, la media de estrenos es de más de tres al mes, por lo que extrapolando los datos podemos suponer, tal vez sea optimista, cerca del medio millar de espectáculos profesionales en el período 1985-1999:

Enero: Día 9. Sala Nasa. A rutina é o deber de todas as criaturas. Chévere. Día 16. Auditorio Municipal de Narón. Amor de Don Perlimplín con Belisa no xardín, de Federico García Lorca, dirigido por Xulio Lago. Teatro do Atlántico. Día 30. Centro Multifuncional de Carballiño. Crímenes anónimos, de Roberto Cerdá. Nove-Dous.

Febrero: Día 9. Teatro Rosalía de Castro. Zocos, de Vicente Montoto y Manuel Lourenzo, dirigido por Manuel Lourenzo. Uvegá Teatro. Día 10. Forum Metropolitano da Coruña. Un home que se parecía a Macbeth, escrito y dirigido por Vicente Montoto. Uvegá Teatro. Día 11. Casa da cultura de Cangas do Morrazo. Lugar común, de Lucía Rodríguez, dirigido por Etelvino Vázquez. Teatro de Ningures. Día 12. 
Casa da Cultura do Barco de Valdeorras. Tics, de Ánxeles Cuña Bóveda, Begoña Muñoz, Fernando Dacosta y Carlos Couceiro, dirigido por Ánxeles Cuña Bóveda. Teatro Sarabela. Día 13. Auditorio do Pazo de Congresos e Exposicions de Pontevedra. Memoria de Antígona, de Quico Cadaval y Xavier Lama, dirigido por Guillermo Heras. Centro Dramático Galego. Día 15. Auditorio Fernando Blanco de Cee. Qui pro Quo, dirigida por Evaristo Calvo. Ollomoltranvía.

Marzo: Día 6. Casa da cultura de Vilagarcía de Arousa. A Casa da América, de Edward Thomas, dirigida por Cristina Domínguez. A Factoría Teatro. Día 18. Sala Galán. Bululú do linier, escrito y dirigido por Cándido Pazó. Teatro do Adro. Día 19. Vilagarcía. Rastros, escrita y dirigida por Roberto Vidal Bolaño. Teatro do Aquí.

Abril: Día 25. Auditorio do Pazo de Congresos e Exposición de Pontevedra. Estación Mahagonny, de Alexandra Moreira da Silva, dirigido por Jorge Castro Guedes. Teatro do Noroeste (en portugués). Día 30. Teatro Rosalía de Castro. Anatomía dun hipocondríaco, escrito y dirigido por Gustavo Pernas. Áncora Produccións.

Mayo: Día 27. Sala NASA. Odisea de Homero, dirigida por Marcelino de Santiago. Monicreques de Kukas. Día 29. Auditorio de Caixa Galicia en Santiago. O Lazariño de Tormes, dirigida por Andrés Pazos y Celso Parada. Teatro do Morcego. Día 31. Sala NASA. Finis mundi circu, dirigida por Quico Cadaval. Mofa e Befa.

\section{MÁS O MENOS PROFESIONAL}

Los datos disponibles sobre el teatro no profesional en Galicia son muy incompletos; en la lista incluida en la guía Teatro, música e danza de Galicia 1999 se citan en el apartado de teatro aficionado 91 grupos, mientras que los datos ofrecidos para el teatro profesional, más fiables, sitúan el número de compañías en 66. De hecho, en la guía sólo aparecen dos grupos de teatro universitario, el Aula de Teatro de la Universidad de Santiago de Compostela y el grupo Teatro da Bufarda, cuando a través de la Revista Galega de Teatro conocemos una docena más. Así pues, la proporción entre teatro de base y profesional no debe de ser tan disparatada como la guía mencionada podría sugerir. 


\section{LAS ESCENAS DE LAS ESCENAS}

También tienen especial importancia en el momento presente los escaparates de nuestra escena por su importante función en la reproducción y distribución de las creaciones.

De 1983 data la primera edición de la Mostra Internacional de teatro cómico e festivo de Cangas. De 1984, la Mostra Internacional de Teatro de Ribadavia. En 1985 se inicia la red de circuitos teatrales de gran importancia para la estabilización de la oferta teatral en múltiples municipios de la Comunidad Autónoma. La Mostra de Teatro no I.B. San Tomé de Freixeiro es de 1988.

En 1993 nace la Feira do Teatro de Galicia, organizada por el IGAEM, punto de encuentro fundamental de compañías y programadores culturales para conjugar la itinerancia en un territorio de gran dispersión geográfica, aunque no pueda resolver algunos males como la falta de espacios escénicos adecuados y el momento en el que se realiza resulte tarde para los programadores que han tenido que cerrar contratos con anterioridad. En la sexta edición, del 17 al 31 de mayo de 1998, se han podido ver 25 compañías. Toda clase de participantes, artistas y programadores, se han constituido en asamblea permanente para, tras reconocer la importancia de la feria, protestar contra la falta de diálogo de la administración que organiza el evento.

En 1993 se ha iniciado la Semana Teatral Ben Veñas Maio, organizada por los Equipos de Normalización Lingüística de Pontevedra.

En 1995 se emprende una colaboración teatral en el marco de la eurorregión Galicia-Norte de Portugal organizada por el Teatro do Noroeste-Centro Dramático de Viana do Castelo y por el Instituto Galego de Estudios e Investigacións Teatrais, que además de organizar una muestra (Festeixo), promueve un espacio para el debate (Teatragal) y un premio de literatura teatral (Premio Eixo Atlántico de textos dramáticos). En 1998 el premio ha ido a parar al gallego João Guisam Seixas por A Tábua Ocre de Núbia, obra escrita en la norma portuguesa por un autor que forma parte de la tradición gallega.

También de 1995 data el Festival Internacional de Teatro Universitario de Santiago de Compostela. Del año siguiente es la Mostra Ibérica de Teatro Universitario en Ourense, organizada por la Aula de teatro universitario de Ourense y Sarabela Teatro, con el patrocinio de la Universidade de Vigo, el IGAEM y el Área de Cultura do Concello de Ourense. 
En 1997 se organizó la Mostra de teatro do Ensino Secundario do Morrazo. 1998 fue el año de la primera Mostra de Danza de Galicia, punto de encuentro de la danza gallega moderna y contemporánea que reunió a 14 compañías, pero también ha sido el año del Compostela Millenium Festival, con el punto de mira de la capitalidad europea de la cultura de Santiago para el año 2000, organizado por el Concello de Santiago en el Auditorio de Galicia, que presentó entre otras propuestas extranjeras los espectáculos de Peter Brook Oh les beaux jours (Samuel Beckett) y Je suis un phénomène (Marie Hélène Estienne y Peter Brook). Del mismo modo, durante el mes de mayo se ha organizado el primer Encontro Internacional de Contadores de Contos promovido por la Agrupación de Amigos do Conto.

Con respecto a los espacios escénicos, la gran revolución de la segunda mitad de los años 90 ha sido la incorporación de lugares insospechados donde el teatro sale al encuentro de los hábitos de ocio de los ciudadanos, mediante la fórmula mixta de introducir el teatro en los establecimientos hosteleros. Así, en Santiago el pub Atlántico, el café-jazz Dado-Dadá, el Apolo, A sá do penal, el pub Ultramarinos o la Sala NASA; en A Coruña, el Garufa, el Terraza, el Marfil, el Jazz Moka, el Corralón, el B.B. King o el café Atlantis; en Carballo, el Silfo; en Ribeira, el Tránsito; en Ferrol, el Intercéltiga; en Lugo, el Clavicémbalo; en Burela, A Zaranda; en Ourense, el Isaac y el Café Central; en Vigo, el Fouce y el Odeón; o en Moaña, el Canis Lupus y el Café do Real.

De todos modos es la conjunción entre Feria y Circuitos la que parece haber abierto más posibilidades de estabilización en la distribución de espectáculos. Durante 1997 había dos circuitos: A (nueve municipios, el Centro Cultural Caixavigo y el Padroado do Teatro Principal de Ourense) y B (18 municipios) (Revista Galega de Teatro 17: contracapa).

En el período comprendido entre octubre y diciembre de 1998 entraron en el circuito teatral de la red de teatros y auditorios otros catorce municipios distintos por los que pasaron 21 compañías. Las de mayor presencia fueron: Teatro do Aquí, 5 municipios (Arteixo, Foz, Moaña, Ponteceso, Porriño); Ollomoltranvía, 3 municipios (Lalín, Moaña, Carral); y en 2 cada una: Teatro do Adro (Arteixo, Foz), Caroza Teatro (Foz, Ares), Mofa e Befa (Foz, Moaña), Encuadre Produccións (Lalín, Xove), Sarabela (Moaña, Xove), Pífano (Porriño, Xove) e Viravolta (Brión, Cartelle) (Revista Galega de Teatro 18: 88). Las dos compañías con mayor presencia en este nuevo circuito habían pasado anteriormente por la Feira de Teatro de Galicia, de modo que parece 
que las dos iniciativas, Feria y Circuitos, pueden complementarse oportunamente.

\section{0. ¡Y RECOGE EL PREMIO..!}

Los premios han ido adquiriendo durante este período una importancia sancionadora tanto, en el sistema teatral como en el de la literatura teatral.

En 1988 se inicia la corta vida del premio de literatura teatral Álvaro Cunqueiro, convocado por la Consellería de Cultura de la Xunta de Galicia en la senda del premio Biblioteca do Arlequín de la editorial Sotelo Blanco un año anterior pero que tampoco tardará en desaparecer. Habrá que esperar a 1991 para que un premio más venga a sumarse a esta línea con el Rafael Dieste de la Deputación Provincial de A Coruña, a la postre el más longevo, que ha llegado ya a su novena edición, premiando por segunda vez a Manuel Lourenzo. Los premios Camiño de Santiago convocados por la Xunta en 1993 y 1994 han sido el último canto del cisne de la década prodigiosa (1984-1994) en la que se mantuvieron las compañías concertadas.

Desde 1997 la Asociación de Actores, Directores e Técnicos de Escena ha organizado los premios María Casares con galardones para actores y actrices principales y secundarios, para textos originales y adaptaciones o traducciones, para directores, iluminadores, sastres, músicos, escenógrafos. También se premia la trayectoria de toda una vida y el mejor espectáculo del año. De este modo se continúa la iniciativa de los Premios Compostela, con los que se inició la década, ya desaparecidos.

\section{FIN DE ACTO}

Contamos con una base poco firme para asentar una panorámica rigurosa de la literatura teatral y del teatro gallegos desde la segunda mitad de los ochenta hasta la actualidad, aunque parezca válido presuponer que el conjunto presenta una unidad temporal. Es siempre demasiado arriesgado hacer pronósticos hacia el futuro, sin embargo 
últimamente empiezan a aparecer indicios que nos hacen sospechar que este período está llegando a su fin; concretamente dos son las pistas que nos llevan a aventurar esta hipótesis: (1) la habilitación de la primera sala estable dependiente del gobierno autonómico, el Salón Teatro de Santiago (otoño de 1999) que puede suponer un importante punto de inflexión en la tradicional itinerancia de nuestro teatro, y (2) el proyecto de creación de la, tan ansiada (Vieites, 1997: contracapa), Escuela Superior de Arte Dramática de Galicia que, si se llega a concretar en lo sucesivo, y el presidente del Consello da Cultura Galega ha dado por hecho ante el Parlamento gallego que empezará a funcionar en el próximo curso 2000-2001, podría suponer una crisis en la dinámica autodidacta que ha caracterizado los últimos tiempos. La reciente des-generación podría dar paso a una auténtica generación nacida al abrigo de esa esperada institución de enseñanza donde los jóvenes gallegos nacidos en los setenta podrían traer nuevos aires a nuestro teatro. ¿Una nueva promoción para el año 2004, la primera generación académica de titulados superiores de una institución teatral gallega? Esperamos que así sea.

\section{Referencias bibliográficas}

\section{A) Libros}

Beramendi, J. G. y NúÑEz SeIXAS, X. M. (1996). O nacionalismo galego.

Vigo: Pormocións Culturais Galegas S.A., 20 ed.

Galicia 1999 (1998). Vigo: Xunta de Galicia.

González-Millan, X. (1994). Literatura e sociedade en Galicia. Vigo: Xerais.

Rodrfiguez, L. y Seara, T. (1997). Para saír do século. Nova proposta poética. Vigo: Xerais.

VIEITES, M. F. (1998a). La nueva dramaturgia gallega. Estudio y antología.

Madrid: Asociación de Directores de Escena de España.

\section{B) Volúmenes colectivos}

Bobes NAVEs, M. del C. (1994). «El teatro». En Curso de teoría de la literatura, D. Villanueva (coord.), 241-268. Madrid: Taurus. 
EQUIPO GLIFO. Grupo compostelán de investigacións semióticas e literarias (1998). Diccionario de termos literarios a-d. Compostela: Xunta de Galicia.

Obelleiro, L. y Alonso, B. (1991). «Idade Contemporánea». En Historia de Galicia, F. Carballo (coord.). Vigo: Promocións Culturais Galegas S.A. Revista Galega de Teatro. Vigo: Asociación Cultural Entre Bambalinas.

VIEITES, M. F. (coord.) (1997). Teoría e técnica teatral. Compostela: Laiovento.

- (ed.) (1998b). Do novo teatro á nova dramaturxia. Vigo: Xerais.

\section{C) Artículos}

AA.VV. (1996). «Teatro gallego». Primer Acto 262, 6-88.

VILAVEDRA, D. (1994). «A escrita dramática galega contemporánea». Grial 122, 207-218.

- (1998). «El teatro gallego después de 1975: una incipiente madurez». Revista de Lenguas y Literaturas Catalana, Gallega y Vasca $V$. Madrid: UNED. 